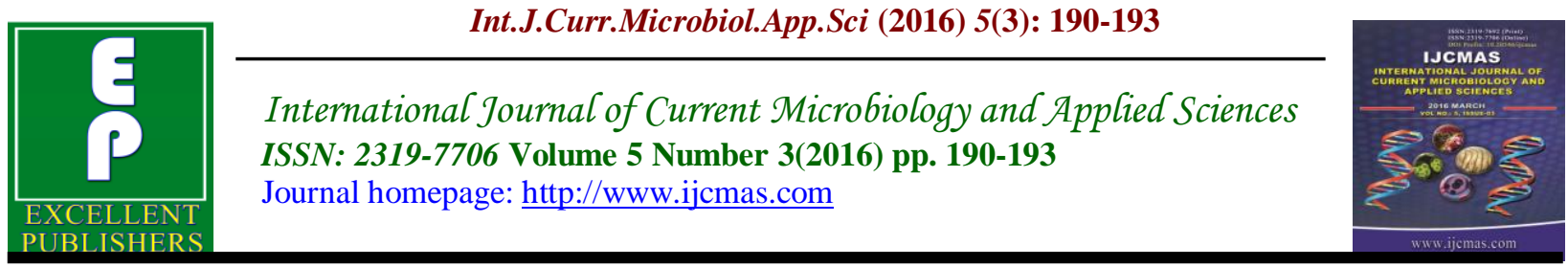

Original Research Article

http://dx.doi.org/10.20546/ijcmas.2016.503.023

\title{
Isolation and Characterization of Lactobacillus casei and in vitro inhibition of enteric pathogens by Lactobacillus casei strains
}

\author{
C. S. Dolas* and K. G. Deshpande \\ Department of Post Harvest and Biotechnology, MGM College of Agricultural \\ Biotechnology, Aurangabad, India \\ *Corresponding author
}

\begin{abstract}
A B S T R A C T
Keywords

Lactobacillus

casei, MRS

media,

Probiotics.

Article Info

Accepted:

15 February 2016

Available Online:

10, March 2016

A lab experiment was carried out in 2012-13 and the main objective of the investigation was, to study in vitro inhibition of enteric pathogens by Lactobacillus casei strains. The experiment was laid outin completely randomized block design with six treatments of test organism such as E.coli, Salmonella typhimurium, Staphylococcus aureus, Pseudomonas aeroginosa, Streptococcus mutans and Control. Supernatant of Lactobacilli grown on Man, Rogosa, Sharpe (MRS) media adjusted $\mathrm{pH}-7$ and unadjusted $\mathrm{pH}$ showed antagonistic response against these test organism. Salmonella typhimurium was significantly superior over rest of other treatments, indicating that supernatant of lactobacili grown on MRS media and adjusted pH-7 showed good antagonistic response against Salmonella typhimurium. Pseudomonas aeroginosa unadjusted pHand Streptococcus mutans unadjusted $\mathrm{pH}$ showed equal antagonistic response. E. coli unadjusted $\mathrm{pH}$ and Staphylococcus aureus adjusted $\mathrm{pH}$ showed equal antagonistic response.
\end{abstract}

\section{Introduction}

Enteric pathogens are a risk factor for gastric adenocarcinoma and lymphoma in humans. In symptomatic patients, the antibiotic treatment has a high cost and is not $100 \%$ effective because of resistance to antibiotics and to moderate patient compliance. This review discusses the role of probiotics as alternative solutions to assist in the control of enteric pathogens colonization in at risk populations.

DPC16 cell-free supernatants (fresh and freeze-dried, designated as MRSc and FZMRSc) from anaerobic incubations in pre-reduced MRS broth, have shown significant inhibitory effects against selected pathogens, including Salmonella typhimurium, E. coli O157:H7, Staphylococcus aureus, and Listeria monocytogenes (Bian, 2008). Probiotics protect against gastrointestinal pathogenic infection via several mechanisms.

Probiotic bacteria have been documented as being effective in biotherapeutic applications against gastrointestinal pathogens, e.g. Helicobacter pylori, Salmonella, Escherichia coli, Listeria monocytogenes, and rotaviruses (Phirabunyanon, 2010). Probiotic lactobacillus rhamnosus strain shows broad 
spectrum activity against GIT pathogens and food spoilage organisms (Pithva et al., 2011).

\section{Materials and Methods}

An experiment was undertaken at the Department of Post Harvest and Food Biotechnology of MGM College of Agriculture Biotechnology Aurangabad. There were six treatments, each replicated thrice.

The treatments comprised of 5 pathogenic bacteria (test organisms) e.g. Escherichia coli, Salmonella typhimurium, Staphylococcus aureus, Pseudomonas aeroginosa and Streptococcus mutans along with Control (without test organism).

Lactobacillus casei was isolated from the curd as described by (Bhardwaj et al., 2012) and were activated by growing thrice on Man, Rogosa, Sharpe (MRS) broth (deMan et al., 1960) at $37^{\circ} \mathrm{C}$ for $24 \mathrm{hrs}$. The test organisms were obtained from MGM medical College, Aurangabad and grown on nutrient agar under anaerobic condition for $72 \mathrm{hrs}$ at $37^{\circ} \mathrm{C}$.

For the experimental purpose, Lactobacillus casei was grown on MRS broth at $37^{\circ} \mathrm{C}$ for $24 \mathrm{hrs}$. The supernatant was then obtained by centrifuging an aliquot at at $4000 \mathrm{rpm}$ for $15 \mathrm{~min}$ at $4^{\circ} \mathrm{C}$. The $\mathrm{pH}$ of supernatant was adjusted to 7.0 (T1-T6) with the use of $2 \mathrm{M}$ $\mathrm{NaOH}$ while another treatments (T7-T12) was unadjusted $\mathrm{pH}$ and it was filtered. Antibacterial activity of the supernatant was measured by food poison method (Amdekar et al., 2010) and expressed as the diameter of inhibition zone.

\section{Results and Discussion}

In this experiment attempts were made to see the antagonistic activity of Lactobacilli isolated from Curd. The results were shown in terms of zone of inhibition.

Among the five test organisms used Lactobacilli was found effective in inhibiting Adjusted $\mathrm{pH}-7$ of Salmonella typhimurium, Staphylococcus aureus, Pseudomonas aeroginosa and unadjusted $\mathrm{pH}$ of E.coli, Salmonella typhimurium, Pseudomonas aeroginosa, Streptococcus mutans which was indicated by zone of test organisms. But it was failed to destruct adjusted pH of E.coli, Streptococcus mutans and unadjusted $\mathrm{pH}$ of Staphylococcus aureus as there was no zone of inhibition in these test organisms.

Salmonella typhimurium (39.25) at $\mathrm{pH}-7$ was significantly superior over rest of the other treatments, indicating that supernatant of lactobacilli grown on MRS media and unadjusted $\mathrm{pH}-7$ showed good antagonistic activity against Salmonella typhimurium were unable show antagonistic response over rest of other test organism.

Pseudomonas aeruginosa (33.50) at $\mathrm{pH}-7$ was at par with Salmonella typhimurium unadjusted $\mathrm{pH}$ and was significantly superior over T3, T7, T10 and T11.

Pseudomonas aeruginosa unadjusted $\mathrm{pH}$ was at par with Streptococcus mutants unadjusted $\mathrm{pH}$ and zone of inhibition was significantly superior over T3 and T7.

E.coli unadjusted $\mathrm{pH}$ and Staphylococcus aureus adjusted at $\mathrm{pH}-7$ was at par with each other, while lactobacillus did not showed any antagonistic effect against T1, T5,T6 and T9. Where zone of inhibition observed was zero. 
Table.1 Treatment Details and Zone of Inhibition of Lactobacilli in Mm against Test Organism

\begin{tabular}{|l|l|l|}
\hline \multicolumn{1}{|c|}{ Treatment (Test organisms) } & \multicolumn{1}{|c|}{ pH } & \multicolumn{1}{c|}{$\begin{array}{c}\text { Diameter of } \\
\text { inhibition } \\
\text { zone }\end{array}$} \\
\hline T1 (E. coli) & $\mathrm{pH}-7$ & 00.00 \\
\hline T2 (Salmonella typhimurian) & $\mathrm{pH}-7$ & 39.25 \\
\hline T3 (Staphylococcus aureous) & $\mathrm{pH}-7$ & 12.50 \\
\hline T4 (Pseudomonas aeroginosa) & $\mathrm{pH}-7$ & 33.50 \\
\hline T5 (Streptococcus mutants) & $\mathrm{pH}-7$ & 00.00 \\
\hline T6 (control) without lactobacillus & $\mathrm{pH}-7$ & 00.00 \\
\hline T7 (E.coli) & Unadjusted & 13.00 \\
\hline T8 (Salmonella typhimurian) & Unadjusted & 30.50 \\
\hline T9 (Staphylococcus aureous) & Unadjusted & 00.00 \\
\hline T10 (Pseudomonas aeroginosa) & Unadjusted & 26.75 \\
\hline T11 (Streptococcus mutants) & Unadjusted & 26.50 \\
\hline T12 (control) without lactobacillus & Unadjusted & 00.00 \\
\hline Mean & & $\mathbf{1 5 . 1 6}$ \\
\hline S.E \pm & & $\mathbf{0 . 7 6}$ \\
\hline CD & & $\mathbf{2 . 1 9}$ \\
\hline
\end{tabular}

Fig.1 Ctobacilli Showed Antagonestic Activity Against Salmonella typhimurium

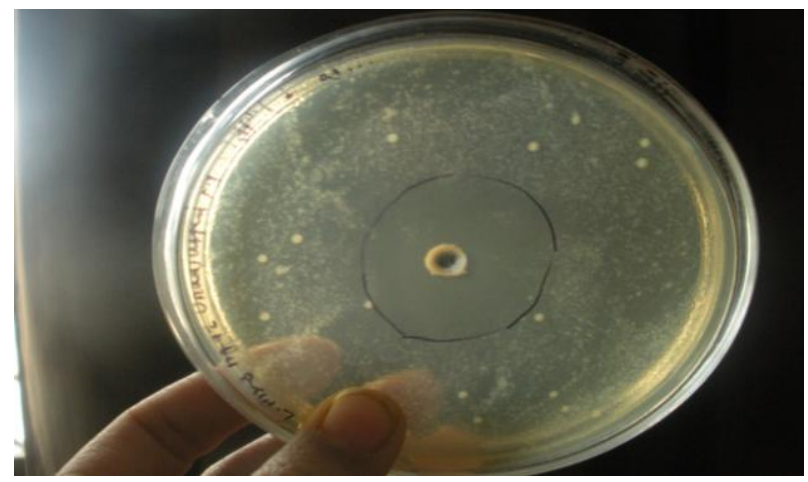

Fig.2 Lactobacilli Showed Antagonistic Activity Against Pseudomonas aeroginosa

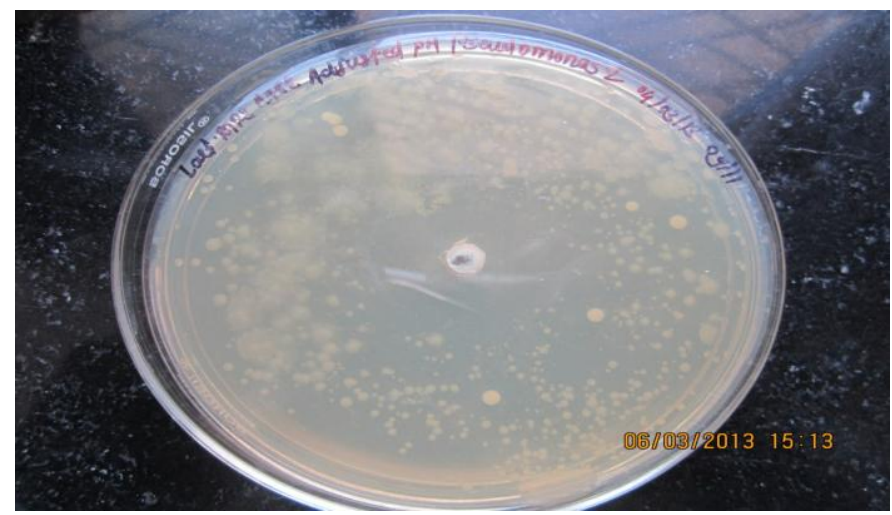


Lactobacilli cells were isolated from the Curd and identified, confirmed by using biochemical test and morphological characters. In this experiment the antagonistic activity of lactobacilli was checked against the enteric pathogens. The test organism such as E.coli, Salmonella typhimurium, Staphylococcus aureus, Pseudomonas aeruginosa, Streptococcus mutans were used in the experiment. It was found that lactobacilli showed significant inhibitory effect against Salmonella typhimurium (Fig.1). It also showed good effect against Pseudomonas aeruginosa, E.coli with unadjusted $\mathrm{pH}$.

Thus we can say that lactobacillus can be used as a biocontrolling agent against the infection of enteric bacteria such as E.coli, Pseudomonas aeroginosa and Salmonella typhimurium. Thus we can prevent the infections by avoiding the use of synthetic antibiotics.

\section{References}

Amdekar, S., Singh, V., Roy, P., Kushwaha, S., Dwivedi, D. 2010. Webmed Cent. Microbiol., 1(9): 1.

Bhardwaj, A., Puniya, M., Sangu, K.P.S., Kumar, S., Tejpal Dhewa, 2012. A J. Dairy Sci. Technol., 1(2): 1.

Bian, L., 2008. An in vitro antimicrobial and safety study of Lactobacillus reuteri DPC16 for validation of probiotic concept .Biotechnology.

DeMan, J.D., Rogosa, M., Sharpe, M.E. 1960. J. Appl. Bact., 23: 130.

Phirabunyanon, M. 2010. Int. J. Sci. Technol., 5(1): 108.

Pithva, S., Mbalam, P.A., Dave, J.M., Vyas, B.R.M. 2011. Antimicrobial Peptides of Probiotic Lactobacillus strains. Dept. Biosci., 987-991.

\section{How to cite this article:}

Dolas, C.S. and Deshpande, K.G. 2016. Isolation and Characterization of Lactobacillus casei and in vitro inhibition of enteric pathogens by Lactobacillus casei strains.

Int.J.Curr.Microbiol.App.Sci. 5(3): 190-193. doi: http://dx.doi.org/10.20546/ijcmas.2016.503.023 